\title{
A changing world: the future for Social Identities
}

Pal Ahluwalia Pro Vice Chancellor (Research and Innovation), University of Portsmouth, Portsmouth, UK

pal.ahluwalia@port.ac.uk

In 1995, when Social Identities was launched, the founding editors set themselves the task of providing a forum for contesting ideas and debates pertaining to the formations of, and transformations in, socially significant identities such as race, nation, ethnicity, gender and class, their attendant forms of material exclusion and power, as well as the political and cultural possibilities these identifications open up. (Goldberg \& Zegeye, 1995).

In the intervening years, the journal has focussed on these themes and takes a very broad interpretation of what constitutes these myriad social identities. This reflection on more than two decades of Social Identities reflects this original mandate and the manner in which we have moved and shaped subsequent debate.

\section{A changing world: snapshots in 1995, 2005 and 2015}

In 1995, the year when Social Identities went into print, monumental changes were taking place. In the previous year, the Rwandan genocide claimed close to million lives and its ramifications were reverberating not only in Africa but around the world. The European Union (EU) was expanding, with Austria, Finland and Sweden joining as members. Mexico was on the verge of financial collapse and it was President Clinton who invoked emergency powers to prevent total financial disaster. A UN tribunal on human rights charged 21 Bosnian Serb Commanders with genocide and crimes against humanity. The Bosnian Serbs undertook mass murder in Srebrenica killing more than 8000 Muslims, the largest such killings since the Second World War. NATO carried out air strikes against Bosnian Serbs near Sarajevo. The UN peacekeeping mission in Somalia was brought to an end largely due to the killings of 18 American soldiers. Timothy McVeigh was responsible for the Oklahoma City bombing. A member of religious right who opposed any peace settlement with the Palestinians assassinated the Prime Minister of Israel, Yitzhak Rabbin.

In 2005, The Palestinian Authority had a new President with the landslide election of Mahmoud Abbas to succeed Yasser Arafat. Condoleeza Rice became the new Secretary of State for the Bush administration. Saudi Arabia held its first civic elections, albeit that women were denied the vote. In that year, Pope John Paul II died. Spain, Belgium and the Netherlands allowed same-sex marriages. The 7/7 
bombing took place in London with four Muslim men taking responsibility. The Provisional Irish Republican Army ended its armed campaign in Northern Ireland. Hurricane Katrina struck the Louisiana, Mississippi and Alabama coasts with extensive damage and carnage in New Orleans. The trail of Saddam Hussein began and the first Parliamentary elections in Iraq were held with a very large turnout.

Twenty years after the launch of Social Identities, it was terrorism that marked 2015, especially in Europe, with the killing of 12 people at Charlie Hebdo by two-masked gunmen. Incredibly, there was an outpouring of people to demonstrate in defiance of the extremism that was signified by the attacks. The slogan 'je suis Charlie' became a global symbol for the freedom of expression. France, however, was further rocked by terrorism when suicide bombers and multiple gunmen killed 130 people in a series of attacks on Paris. The terror attacks were not limited to Europe but extended to Mali with an attack on the Radisson Blu hotel. The response was a concerted attack on Islamic State strongholds, leaving the world in a precarious balance as the threats of terrorism loomed large over Europe. The Mediterranean migrant crisis shocked the world when over 800 people died as a result of a boat capsizing. The Greek financial crisis ensued when Greece was unable to meet debt repayment deadlines set by the International Monetary Fund. The US and Cuba agreed to open embassies after 50 years of hostility. The body of a drowned toddler was found on a Turkish beach sparking a wave of sympathy for Syrian refugees who were escaping intolerable conditions at home.

\section{Social Identities: snapshots in 1995, 2005 and 2015}

Social Identities began in 1995 by publishing two issues, and a cursory glance at the table of contents reveals the range of articles that were published on the choices of identity, on food, forced labour, perceptions of identity in Modern China, the relationship between post-colonialism and ethnicities, memory and identity in the age of commodification, German identity, reproductive politics in Eastern Europe, racism in film and a reflection of critical mixed race. By the next year the journal had expanded to three issues a year and by 1999 it moved to having 4 issues. In its 10th year of production, 2004, Social Identities had become highly popular and had moved to its current six-year format.

When Toby Miller and I took over the journal in 2005, some of the realities and responsibilities bequeathed to us rapidly became apparent and a partnership of mutual respect and trust in the intervening years has endured. In our first editorial, we noted that the founding editors had 'nurtured the journal, making it today a key publication in the field'. We went on to note, 'Social Identities has been attuned not only to the events in the contemporary world, but also to major trends within social theory' (Ahluwalia \& Miller, 2005). We saw it 'as a forum where challenging and radical ideas that disrupt the certainty of orthodox thinking are exchanged' (Ahluwalia 
\& Miller, 2005). Furthermore, we were deeply aware of the monumental changes that were taking place in the world including intense globalisation, especially in financial and communications terms. Equally, we were attuned to the aftermath of the 9/11 attacks and the relentless war on terror that affected so many countries. We recognised that it was essential that the journal keep abreast 'of the changing dynamics of contemporary social theory, to be able to respond to the very challenges that our world presents to its different subjects, both in the West, as well as in the Post-colony' (p. 2).

In order to reflect this continuity and change, and in keeping with our commitment to reflecting both what was happening in the world, coupled with changes in social theory, the issues in our first year focussed on cultural divisions and Muslim identity, women's everyday life in the city, sovereign power in Burundi, notions of mixed race, constructing social identities in South African media, contemporary radio in subSaharan Africa, dialogue as the inscription of the West, Rousseau's Orientalism, diasporic identities, gay identities, multi-racial identities in the post civil rights era, whiteness and the construction of 9/11, gender, and perceptions about skin colour.

Ten years later, in 2015, Social Identities had significantly expanded its remit as can be seen by the scope of material published that year ranging from disability and colonialism, religion and violence, indigenous land rights, necronationalism, ethnic melancholy in cinema, citizenship, refugees, black identities, Charlie Hebdo, masculinities, migration, discourses of human rights, space and identity, hip-hop culture, media and blackness, Asian Britain, Korean identities and diaspora, multiculturalism, shifting identities in China, and right wing populism.

Clearly, the world in the more than two decades since Social Identities was launched has rapidly changed. Significant global events have taken place that will necessitate new explanations, theoretical innovations and political sensibilities in what can best be described as a highly complex world in which we find ourselves. In June 2016, following a hard fought campaign for the future of the UK's membership of the European Union, the decision to leave following a referendum was adopted. This was a momentous, albeit close decision, where $52 \%$ of the voting population determined the fate of all UK citizens. Although the UK has not formally moved to exit the EU, the ramifications of the decision continues to be extensive. It has cost the former Prime Minister David Cameron his job, and a new PM, Theresa May, and cabinet has been chosen, with those wishing to leave rewarded. The UK economy has suffered, as predicted by the Treasury, and the currency markets have reacted with the pound being at its weakest in over thirty years. However, it is not only the economy and UK politics that have been radically altered.

A referendum that ultimately became bogged down over the issue of migration and refugees, as well as the inability to control one's borders, challenged the very assertion that ever-increasingly we now live in an integrated, connected and 
interdependent world. The 'leave decision' has also resulted in an unprecedented increase in race motivated attacks across the country and seemed to be the licence to return to the racism of the 1970s. Going forward, we will need to consider the implications of Brexit, for globalisation, and the very idea of the free movement of goods and people. It may take nearly a decade for the UK to leave the EU, as the process of disentanglement takes places. Nevertheless, the idea of Europe, which was vital to its stability and prosperity, is itself shaken. Brexit seems, on the face of it, a regression and a triumph of nationalism over any sense of European, regional or global integration.

On the other side of the Atlantic, Donald Trump has been elected President signalling a new type of politics with a rise in jingoism and nationalism that has been unprecedented. He has significantly changed the manner in which the Presidency operates and 'fake news' has entered the lexicon. Trump is a President who communicates policy and directives through twitter and executive orders with scant attention to Washington's protocols and conventions. At the time of writing, he had issued 27 such orders. The most controversial is the order that suspends the refugee programme and entry to the US for travellers from certain Muslim countries. The Trump Presidency has also given rise to more ultra right wing nationalists in Europe with the French and German elections likely to be affected. The perceived Islamic threat and migration seem to be the key to the rise of these politicians.

It should not be surprising then that migration and notions of multiculturalism will continue to have a significant salience for us at Social Identities. As Meer and Modood, drawing upon Beck's (Beck, 2001) notion of zombie categories, that is, 'living dead' categories which govern our thinking but are not really able to capture the contemporary milieu,' argue, multiculturalism will need to be reconceptualised (Beck, 2001). They are referring to the very multiculturalism that Beck had proclaimed dead by virtue of cosmopolitan theory and practice. The point they make is that, 'while multiculturalism may be a zombie term, it is far from a zombie category' (p. 13). They are keen to illustrate how resilient and relevant multiculturalism could be in certain places. This is certainly the case in both Australia and Canada, where it appears to be well and alive, especially as a political phenomenon.

A key aspect of this debate is whether a zombie term, multiculturalism or indeed a host of alternative terms and concepts including interculturalism, can capture the diversity and plurality prevalent within our communities, especially in our urban spaces where globalisation and technology are such a dominant influence on the practice of everyday life.

Nevertheless, I suspect that such debates are vital to our understanding of the national versus global tendencies that dominate our contemporary condition. The large numbers of post-colonial subjects in metropolitan nations has led to considerable social and cultural transformation 'and has consequently laid the ground 
for a series of textual transformations' (Dhouib, 2014). Textual transformations in contemporary black writing in Britain.

Perhaps the most important change has been that identity formation and the very manner in which people conceptualise themselves has altered. It may well be that multiculturalism is reminiscent of a separation of diasporic identities which located individuals in two distinct places. Given the kind of cosmopolitan identities that are now so prevalent, it may well be far more appropriate to use Vijay Prashad's term 'polyculturalism' 'as it takes into account the sensibilities of fusion rather than mere co-existence' (Dhouib, 2014). This offers an alternative lens in which to engage the world from, where there is no harking for a lost land but rather engaging the world from 'home', the only 'home' that they know.

In the Australian case, there has been a tendency in some circles to apply the term multiculturalism to signify 'ethnic' communities, rather than what it is meant to be, a descriptor of Australian society as a whole. This confusing position takes us back in time to the period of the 'integration' philosophy of the 1960s and 1970s, which again found favour in the 1990s. As the critics of that resurgence have argued, such an approach undermines community cohesiveness by promoting difference negatively through an 'us and them' approach. Whereas it should be an inclusive definition in which all of us are seen to be contributors to a 'multicultural' society. To that end, we need to avoid, for example, saying we are becoming more multicultural as new migrant groups arrive. It is a little like saying that something that is undeniably good is 'more good'.

To take this notion further, a critical challenge is to shun a silo approach to these agendas. Rather, we should be striving to create empowered communities by weaving together the principles that apply in each case: that we are complex communities in which respect for difference is embedded; that we aim to ensure that all are able to be included through effective social inclusion policies and action; and that we are all entitled to human dignity and to the rights and responsibilities that flow from that.

These ideas need to be regularly projected and hopefully absorbed by society at large and particularly through education. We have seen what happens when the official messages become skewed to suggest that there are 'legitimate' Australians, Americans or Britons and then there are 'others', and we continue to see the effects of the erosion of the principles of accepting and respecting diversity. The idea of 'queue jumpers' is something that seems to have entered our lexicon and might cause lasting damage. This must be resisted, and our approach to humanitarian entrants should always be to emphasise the values that we espouse as a nation, both as part of their empowering process, but more importantly as a way of re-affirming our own acceptance of diverse peoples.

There is little doubt that we are living in 'unsettling' times that require new theoretical interventions as we struggle to recognise the social, cultural and religious differences 
that are constitutive of complex multicultural societies. In the new configuration of politics, the influence of the media and its impact on identity formation will need to be conceptualised in new and innovative ways. The continuing impact of global terrorist networks will continue to challenge our sensibilities and the relation between place and identity as a result of the global flows of peoples will change our contemporary understandings of migration, citizenship, diasporas and notions of belonging. I look forward to the next phase of Social Identities, where these issues will be debated and contested.

\section{Disclosure statement}

No potential conflict of interest was reported by the author.

\section{References}

1. Ahluwalia, P., \& Miller, T. (2005). Editorial note: Continuity and change. Social Identities, 11(1), 1-3. doi: 10.1080/13504630500100365

2. Beck, U. (2001). Interview with Ulrich Beck. Journal of Consumer Culture, 1(2), 261-277. doi:10.1177/146954050100100209

3. Dhouib, J. A. (2014). Textual transformations in contemporary black writing in Britain. Advances in Language and Literary Studies, 5(2), 120-126.

doi: 10.7575/aiac.alls.v.5n.2p.120

4. Goldberg, T., \& Zegeye, A. (1995). Editorial note: Social identities. Social Identities, 1(1), 3-4. doi: 10.1080/13504630.1995.9959422

5. Meer, N., \& Modood, T. (2014). Cosmopolitanism and integrationism: Is British multiculturalism a 'zombie category'?!dentities, 21(6), 658-674.

doi: 10.1080/1070289X.2013.875028 